\title{
The effect of translational and rotational relative velocity components on fluid-to-particle heat transfer coefficients in continuous tube flow
}

\author{
P. N. Baptista, ${ }^{a}$ F. A. R. Oliveira, ${ }^{a}$ J. C. Oliveira ${ }^{a} \&$ S. K. Sastry ${ }^{b}$ \\ ${ }^{a}$ Escola Superior de Biotecnologia, Universidade Católica Portuguesa, Rua Dr. António Bernardino de Almeida, 4200, Porto, Portugal \\ ${ }^{h}$ Ohio State University, Agricultural Engineering Department, 590, Woody Hayes Drive, Columbus, OH 43210, USA
}

\begin{abstract}
A liquid crystal technique was used to determine average fluid-to-particle heat transfer coefficients $(h f p)$ for single spherical hollow aluminium particles heating in carboxymethylcellulose solutions in continuous tube flow. The particles' linear and rotational velocities were also measured by videotaping the particle motion at a bottom position. Particles with different diameter and density were used in solutions with different viscosities and at different flow rates $(7<$ Reynolds $<284 ; 144<$ Prandtl $<1755)$. The values of the average heat transfer coefficient were between 334 and $1497 \mathrm{~W} / \mathrm{m}^{2} \mathrm{C}$. The results showed that both the relative fluid-to-particle velocity and the particle rotational velocity influence the heat transfer coefficients, although it is not possible to individualize their effects. However, the addition of the individual effects, predicted by using published dimensionless correlations, yielded a good fit with the experimental values.
\end{abstract}

Keywords: dimensionless correlations, heat transfer coefficient, particles rotational velocity, relative fluid-to-particle velocity.

\section{NOMENCLATURE}

a Coefficients of the calibration curves for the

$b, c$ particles coating

Ap Surface area of the particle $\left(\mathrm{m}^{2}\right)$

$C p_{f}$ Specific heat of the fluid (J/(kg.C))

$C p_{p}$ Specific heat of the particle (J/(kg.C))

$h_{f p} \quad$ Fluid-to-particle heat transfer coefficient (W/ $\left.\left(\mathrm{m}^{2} . \mathrm{C}\right)\right)$

$H$ Hue value

$K \quad$ Consistency coefficient of fluid $\left(\mathrm{Pa} \mathrm{s}^{\mathrm{n}}\right)$

$k_{f}$ Thermal conductivity of the fluid (W/(m.C))

$k_{p}$ Thermal conductivity of the solid particle (W/ (m.C))

$L \quad$ Thickness of the particle $(\mathrm{mm})$

$m_{p} \quad$ Mass of the particle $(\mathrm{kg})$

$n \quad$ Flow behaviour index of fluid

$N$ Number of particle rotations (rotations/s)

$Q \quad$ Flow rate $(\mathrm{L} / \mathrm{h})$ $r_{p} \quad$ Radius of the particle $(\mathrm{m})$

$R_{o} \quad$ Distance between tube and particle center $(\mathrm{m})$

$\mathbf{R}_{\mathrm{t}} \quad$ Radius of the tube (m)

$t$ Time (s)

$T$ Temperature of the particle $\left({ }^{\circ} \mathrm{C}\right)$

$T_{f} \quad$ Temperature of the fluid $\left({ }^{\circ} \mathrm{C}\right)$

$T_{i} \quad$ Initial temperature of the particle $\left({ }^{\circ} \mathrm{C}\right)$

$v f a$ Average velocity of the undisturbed fluid in the projected area of the particle $(\mathrm{m} / \mathrm{s})$

$v_{f p} \quad$ Relative fluid-to-particle velocity $(\mathrm{m} / \mathrm{s})$

$v_{p} \quad$ Particle velocity $(\mathrm{m} / \mathrm{s})$

$W \quad$ Percent water content

\section{GREEK LETTERS}

$\gamma \quad$ Shear rate $\left(\mathrm{s}^{-1}\right)$

$\mu \quad$ Fluid viscosity (Pa s)

$\rho_{p} \quad$ Particle density $\left(\mathrm{kg} / \mathrm{m}^{3}\right)$

$\tau \quad$ Shear stress $(\mathrm{Pa})$

$\omega$ Particle rotational velocity $(\mathrm{m} / \mathrm{s})$ 


\section{DIMENSIONLESS NUMBERS}

$B i \quad$ Biot Number

Gr Generalized Grashof Number for zero fluid velocity

$$
\left(\frac{d_{p}^{3} g \beta \rho_{f}^{2}\left(\frac{T_{a v}-T_{v}}{2}\right)}{\mu_{v=0}^{2}}\right)
$$

$N u \quad$ Nusselt Number $\left(h_{f p} d_{p} / k_{f}\right)$

$\mathrm{Nu}_{s}$ Nusselt Number for natural convection

$\mathrm{Prg}_{\mathrm{g}}$ Generalized Prandtl Number

$$
\left(\frac{C p f K\left(\frac{3 n+1}{n}\right)^{n} 2^{n-3}}{k_{f}\left(\frac{v}{d_{p}}\right)^{1-n}}\right)
$$

\section{$\operatorname{Pr}_{g \omega}$ Generalized Prandtl Number for rotational velocity \\ $\operatorname{Pr}_{s}$ Generalized Prandtl Number for zero fluid velocity $\left(C p_{f} \mu_{v=0} / k_{f}\right)$ \\ $R e_{g}$ Generalized Reynolds Number}

$$
\left(\frac{8 \rho f v^{2-n} d_{p}^{n}}{2^{n} K\left(\frac{3 n+1}{n}\right)^{n}}\right)
$$

$R e_{g \omega}$ Generalized Reynolds Number for rotational
velocity

\section{INTRODUCTION}

Although the thermal processing theory is well established, the determination of fluid-to-particle heat transfer coefficients $\left(h_{f p}\right)$ during continuous tube flow is complex due to the difficulties in measuring accurately the temperature of moving particles without disturbing the flow conditions.

Initially, a conservative approach based in a non-flow or stationary condition was proposed (Dignan et al., 1989) to estimate $h_{f p}$. However, experimental $h_{f p}$ obtained by several authors in flow conditions (Table 1) clearly show that this approach is very conservative. This may be justified by the fact that fluid and particle usually exhibit different velocities (Sastry et al., 1990; Dutta \& Sastry, 1990a,b; Palmieri et al., 1992; Zitoun \& Sastry, 1994a) resulting in a relative fluid-to-particle velocity and thus promoting forced convection between fluid and particle. Furthermore, the particles often present a rotational movement that affects the boundary layer and probably increases the $h_{f p}$ values. Balasubramaniam (1993), Zitoun (1993) and Zitoun and Sastry $(1994 a, b)$, using three different methods to measure $h_{f p}$ (liquid crystal, relative velocity and moving thermocouple methods), systematically obtained lower values of $h_{f p}$ with the moving thermocouple method. In this method, a thermocouple is attached to the particle and withdrawn from the downstream end at the same velocity as the particle should have if free. Therefore, in these conditions, the particle does not rotate, which may justify the lower $h_{f p}$ values and stresses the effects of rotational movements on heat transfer rates. The liquid crystal technique was initially used by Stoforos and Merson (1990), Stoforos and Merson (1991, 1992) to estimate $h_{f p}$ in rotating liquid/particulate systems such as cylindrical vessels. Several other studies on $h_{f p}$ were carried out in non continuous tube flow (e.g. Rao et al., 1985; Awuah et al., 1993; Sablani \& Ramaswamy, 1995). Åström and Bark (1994) studied heat transfer in still particles immersed in a liquid bath with walls rotating at different speeds. Baptista et al., (1997) reported $h_{f p}$ values for spherical particles rotating in an otherwise stagnant fluid and developed dimensionless correlations for these conditions. A similar situation had been previously analysed, although for mass transfer (Noordsij \& Rotte, 1967).

The main objectives of this work were (1) to verify the importance of relative fluid-to-particle velocity and of the particle rotational velocity in the $h_{f p}$ in continuous tube flow and (2) to assess the usefulness of dimensionless correlations previously developed for still particles immersed in a moving fluid and for particles rotating in an otherwise stagnant fluid for the prediction of fluid-to-particle heat transfer in continuous tube flow.

\section{MATERIALS AND METHODS}

\section{Particles}

Hollow spheres with different diameters and densities made with the aluminum alloy 6061-T6561 were used $\left(k_{p 25^{\circ} \mathrm{C}}=180 \mathrm{~W} / \mathrm{m} . \mathrm{C} ; C p_{p 20^{\circ} \mathrm{C}}=896 \mathrm{~J} / \mathrm{kg} . \mathrm{C} ; \rho_{p}=2700\right.$ $\mathrm{kg} / \mathrm{m}^{3}$ (ASM, 1979)). The desired densities were obtained by using different wall thicknesses. Prior to the particle coating, a Teflon fine gauge copper-constantan thermocouple (TT-T-36, OMEGA, Stanford,(CT, USA) was welded to the inner wall of the particle. A suspension of encapsulated liquid crystal was sprayed over the particle surface, pre-coated with a black paint (Sprayblack Back BB-MI, Hallcrest, Glenview, Il, USA) to absorb light transmitted through the liquid crystal and provide a good viewing contrast. This suspension was previously prepared mixing one part of liquid crystal (BM/R25Cl0W/S40, Hallcrest, Glenview, Il, USA) with four parts of aqueous binder (AQB-3, Hallcrest, Glenview, Il, USA) and stored in a refrigerated environment. An air brush was used in both coatings to provide an homogeneous and smooth surface, preventing the possibility of light scattering in the surface (Moffat, 1990). 


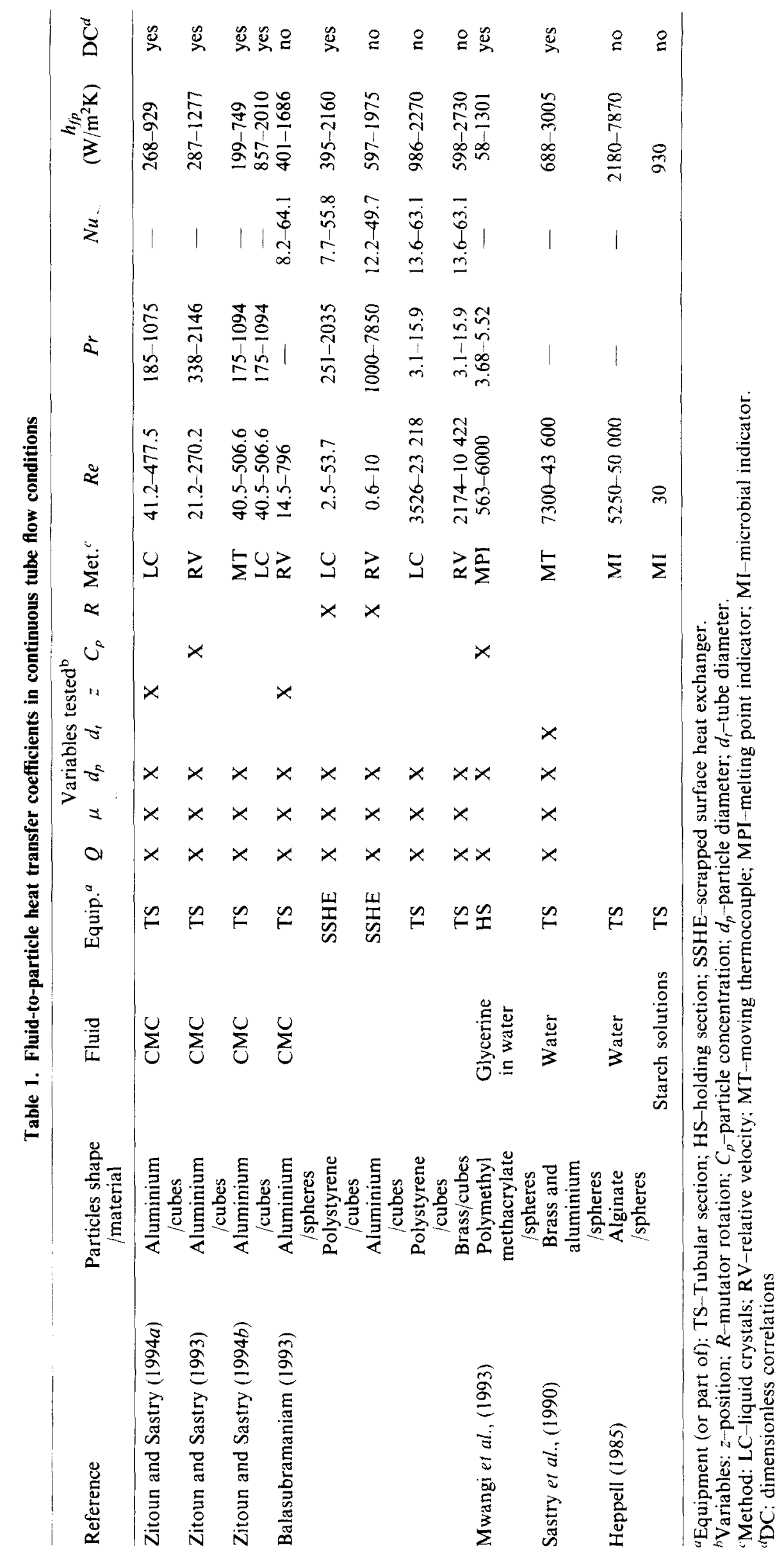




\section{Fluid}

Non-Newtonian sodium carboxymethylcellulose (CMC) solutions (CMC-70-G, Aqualon Co., Wilmington, DE, USA) were used. The CMC powder was slowly added to water at $37^{\circ} \mathrm{C}$ with continuous stirring, for at least two hours, until complete dissolution. A power law behaviour was assumed and the consistency coefficient $(K)$ and the flow behaviour index $(n)$ of the solutions were determined using a coaxial cylinder viscometer (Rheomat Model 115, Contraves Industrial Division, Cincinnati, OH, U.S.A). In order to ensure that no substantial shear breakdown occurred during the experiments, the rheological properties were measured at the beginning, at the middle and at the end of each set of experiments. Table 2 shows the consistency coeffcients and flow behaviour indexes obtained for the CMC solutions used at $37^{\circ} \mathrm{C}$. The density of the solutions was $1.00+0.01 \mathrm{~g} / \mathrm{cm}^{3}$ and their thermal conductivity and specific heat were estimated using the correlations proposed by Heldman and Singh (1981):

$$
\begin{gathered}
k_{f}=\left[326.575+1.0412 T_{f}-0.00337 T_{f}^{2}\right] \\
*[0.796+0.009346 * W] * 10^{-3}\left(\mathrm{~W} / \mathrm{m}^{2} . C\right) \\
C p f=1.675+0.025 * W(\mathrm{~kJ} / \mathrm{kg} . \mathrm{C})
\end{gathered}
$$

where $W$ is the percent water content.

\section{Experimental procedure}

The experimental system used is schematically represented in Fig. 1. The CMC solution, prepared in a stirred jacketed tank (ST) with temperature control at $37^{\circ} \mathrm{C}$, was pumped through the tubular transparent section of the system with a positive displacement lobe pump (P) (Waukesha Sanitary Pump size 25, Waukesha Foundry Co., Waukesha, WI, Canada) and recycled to the tank.

To calibrate the liquid crystal, each particle was individually equilibrated in similar conditions to the experimental runs, placing the particle stationary in the fluid flowing in the system (Fig. 1) at $37^{\circ} \mathrm{C}$. The temperature signal was captured through the welded thermocouple in a data logger $(21 \times$ Micrologger, Campbell Scientific

\begin{tabular}{|c|c|c|}
\hline $\begin{array}{l}\% \\
\mathrm{CMC}\end{array}$ & $\begin{array}{c}K \\
\underset{\left(\mathrm{Pa} . \mathrm{s}^{n}\right)}{\text { Consistency index }}\end{array}$ & $\begin{array}{c}n \\
\text { Flow behaviour } \\
\text { index }\end{array}$ \\
\hline 0.20 & $0.082 \pm 0.001$ & $0.71 \pm 0.01$ \\
\hline 0.40 & $0.42 \pm 0.03$ & $0.60 \pm 0.01$ \\
\hline 0.60 & $1.04 \pm 0.02$ & $0.54 \pm 0.01$ \\
\hline
\end{tabular}

Table 2. Shear-stress characteristics of the CMC solutions at $37^{\circ} \mathrm{C}^{*}$ (average and standard deviation fo five replicates)

${ }^{*} \tau=K * \gamma^{n}$ Shear rate range: 6.65 to $1008 \mathrm{~s}^{-1}$.
Inc., Logan, UT) and the colour change videotaped. Selected VCR images from the videotape were fed through an RGB (red, green and blue) decoder to a computer. An image analysis software (Image-Pro, Media Cybernetics, Silver Spring, MD) was used to measure the colour change value (hue value $-H$ ). For each particle, three calibrations were carried out, with the particle visualized in different positions, to minimize the effects of less homogeneous coatings. The data for each particle were used to calibrate the colour temperature response $(T)$ of the liquid crystal using a 2 nd order polynomial. The calibration equations are only valid for the specific particle in the range of particle temperature variation.

The thermocouple used to calibrate the liquid crystal on the particle surface was then removed and the particles pre-cooled in a water/ice mixture to a temperature between 0 and $1^{\circ} \mathrm{C}$ before each experimental run. A single particle was introduced rapidly at the entry section (ES), a transparent $T$-tube with an internal diameter of $5.08 \mathrm{~cm}$. This section was attached to the main section (MS), a straight transparent tube of $1.5 \mathrm{~m}$ length and $1.19^{\circ}$ inclination. The flow rate was measured by a magnetic flowmeter (FM) (Model 8712 CR12M4, Rosemount, Eden Prairie, MN) and the fluid temperature at the inlet of the transparent section by a copperconstantan thermocouple (TC), both being recorded continuously in a data logger (DL).

\section{$h_{f p}$ determination}

Assuming that the internal resistance to heat transfer is negligible compared to the resistance due to the convection at the particle surface $\left(B i=h_{f p} L / k_{p}<0.1\right)$, the heat transfer equation becomes:

$$
\ln \left[\frac{\left(T-T_{f}\right)}{\left(T_{i}-T_{f}\right)}\right]=-\left(\frac{h_{f p} A_{p}}{m_{p} C p_{p}}\right) t
$$

The $h_{f p}$ obtained by linear regression. The Biot number was calculated to ensure the validity of the assumption.

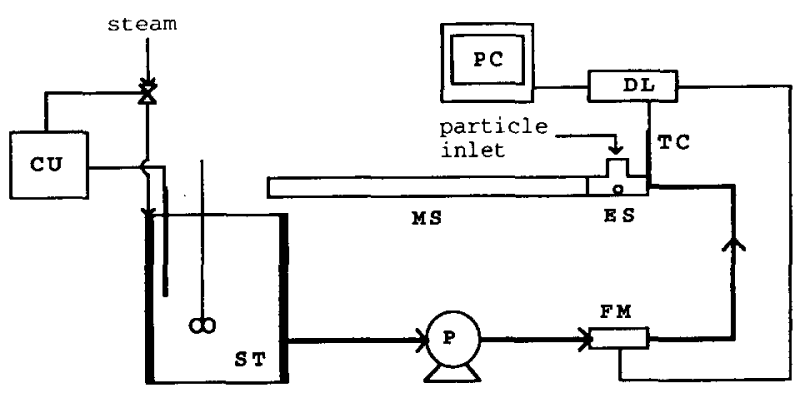

Fig. 1. Experimental set-up for the determination of fluid-toparticle heat transfer coefficients in continuous tube flow. CU-Temperature control unit; DL-Data logger; ES-Particle entry section; FM-Magnetic flowmeter; MS-Main section; P-Pump; PC-Personal computer; ST-Stirred jacket tank; TC-Copper-constantan thermocouple 


\section{Fluid-to particle relative velocity and particle rotational velocity determination}

Both linear and rotational velocities were measured in different sections of the tube, and the process was only analysed after constant velocities were reached. The linear velocity of the particle, $v_{p}$, was determined by playing the videotape in slow motion and measuring the ratio between travelled length and time. The relative fluid-to particle velocity $\left(v f_{p}\right)$ was evaluated as the module of the difference between $v_{p}$ and the average velocity of the undisturbed fluid in the projected area of the particle, $v_{a a}$ :

$$
\begin{aligned}
v_{f p}=\left|v_{p}-v_{f a}\right|=\mid v_{p} & -v_{o}\left[1-\frac{1}{2}\left(\frac{r_{p}}{R_{t}}\right)^{2}\right. \\
& \left.-\frac{8}{3 \pi} \frac{R_{o} r_{p}}{R_{t}^{2}}-\left(\frac{R_{o}}{R_{t}}\right)^{2}\right] \mid
\end{aligned}
$$

where $r_{p}$ is the radius of the particle, $R_{t}$ the radius of the tube and $R_{o}$ the distance between the tube and particle center.

In the same length and time interval used before, the number of rotations, $N$, of a point at the surface of the particle was counted and the rotational velocity of the particle $(\omega)$ evaluated as:

$$
\omega=2 N \pi r_{p}
$$

\section{The experiments}

Thirty-two experiments were performed for different single particles immersed in different solutions running at various flow rates. Some combinations of the different variables were not possible as, for those conditions, the particle would be almost stationary, or would not flow at the bottom of the tube. Four replicates were performed for each set of experimental conditions. A paired difference experiments analysis (Walpole \& Myers, 1993) was performed to assess the effect of the diferent variables tested on $h_{f p}, v_{f p}$ and $\omega$. The paired difference analysis was considered to avoid biased results due to systematic differences between experimental units. For each difference, the two experiments considered had the same values of all variables except the one that was the subject of the analysis.

\section{RESULTS AND DISCUSSION}

The experiments were conducted in the laminar flow regime (generalized Reynolds numbers between 7 and 284), with Prandtl numbers between 144 and 1755 . The $h_{f p}$ between 334 and $1497 \mathrm{~W} / \mathrm{m}^{2}$.C were obtained. The Nusselt number varied between 11.3 and 49.5. These values agree well with others reported in literature (see Table 1) and clearly show that assuming stationary conditions would be too conservative. The particle rotational velocity varied between 0.019 and $0.137 \mathrm{~m} / \mathrm{s}$, while the relative fluid to particle velocity was between 0.0013 and $0.066 \mathrm{~m} / \mathrm{s}$. The latter values are of the same order of magnitude of those published by Balasubramaniam (1993) although, in general, higher, which may be explained by the different techniques used for measuring the fluid velocity. For low flow rates, it was observed that the particle linear velocity was, generally, lower than the average fluid velocity in the position of the particle, while the opposite was observed for higher flow rates.

The effect of particle diameter could not be assessed because there were some technical limitations in making particles with different diameters and exactly the same density. The effects of the other variables tested on $h_{f p}$, $v f_{p}$ and $\omega$ are summarized in Table 3 . It can be concluded that, in general, increasing the flow rate or decreasing the fluid viscosity has a positive effect on the $h_{f p}$, as well as on the particle rotational velocity. The effect of the particle density was less evident, but it was clear that increasing the particle density from approximately 1.26 to $1.43 \mathrm{~g} / \mathrm{cm}^{3}$ also increased the $h_{f n}$ and $\omega$. In terms of $v_{f p}$, on the other hand, no significant effects were detected. The effect of fluid viscosity can be easily understood because this variable is expected to have a direct influence on the boundary layer around the particle, therefore affecting the heat transfer process. The effect of the flow rate and the particle density, on the other hand, may be related to their influence on the particle rotational velocity. In fact, particle density does not affect the heat transfer process directly and, so far, it has not been considered in any of the published correlations for estimating heat transfer coefficients. These results are, however, in agreement with those reported by Zitoun and Sastry (1994a), who studied the effect of radial

Table 3. Effects of the variables studied on the fluid-to-particle heat transfer coefficient, on the fluid-to-particle relative velocity and on the particle rotational velocity*

\begin{tabular}{lcccc} 
Variable & Range & $h_{f p}\left(\mathrm{~W} / \mathrm{m}^{2} \mathrm{~K}\right)$ & $v_{f p}(\mathrm{~m} / \mathrm{s})$ & $\omega(\mathrm{m} / \mathrm{s})$ \\
\hline Flow rate & $681 \rightarrow 1363$ & $95 \%(+)$ & n.s. & $99 \%(+)$ \\
$(\mathrm{L} / \mathrm{h})$ & $1363 \rightarrow 2044$ & $99 \%(+)$ & n.s. & $95 \%(+)$ \\
Viscosity & $0.2 \rightarrow 0.4$ & $99 \%(-)$ & n.s. & $99 \%(-)$ \\
$(\%$ CMC) & $0.4 \rightarrow 0.6$ & n.s. & n.s. & $95 \%(-)$ \\
Particle density $\left(\mathrm{g} / \mathrm{cm}^{3}\right)$ & $1.26 \rightarrow 1.43$ & $95 \%(+)$ & n.s. & $95 \%(+)$ \\
\hline
\end{tabular}

(Data refer to 32 sets of operating variables, each replicated four times, in a total of 128 experimental points).

${ }^{*}$ n.s.-Not significant (confidence level lower than $95 \%$ ); $9 \mathrm{X} \%(+)$ - Increasing the variable the parameter increases, with a $9 \mathrm{X} \%$ confidence level; $9 \mathrm{X} \%(-)$ - Increasing the variable the parameter decreases, with a $9 \mathrm{X} \%$ confidence level. 
position on the $h_{f p}$ for cubic particles. These authors found the $h_{f p}$ values increased from the center to the wall of the tube, where both the rotational and fluid-toparticle relative velocities were higher.

In a previous work, Baptista et al., (1997) developed dimensionless correlations for still particles immersed in a bottom position in tube flow, obtaining:

$$
N u=N u_{s}+0.64 * R e_{g}^{0.59} * P r_{g}^{0.28}
$$

where $N u_{s}$ is the Nusselt number for stagnant conditions:

$$
N u_{s}=2.0+0.025 * P r_{s}^{1 / 3} * G r^{1 / 2}
$$

where $\operatorname{Pr}_{s}$ is the generalized Prandtl number for zero fluid velocity and $G r$ the generalized Grashof number.

Correlations for the heat transfer coefficient of particles rotating in an otherwise stagnant fluid were also obtained by Baptista et al., (1997):

$$
N u=N u_{s}+0.17 * R e_{g \omega}^{0.71} * \operatorname{Pr}_{g \omega}^{0.42} *\left(r_{p} / R_{t}\right)^{0.28}
$$

where $r_{p} / R_{t}$ is the ratio between the particle and the tube diameter.

These correlations were obtained in similar ranges of the dimensionless numbers used in this work. However, both would greatly underpredict the heat transfer coefficient obtained in this work. It was then considered that the effects of the linear relative velocity and the rotational velocity might be additive. This implies that the experimental values could be predicted simply by adding eqns $6-8$, except for the common term $N u_{s}$. The

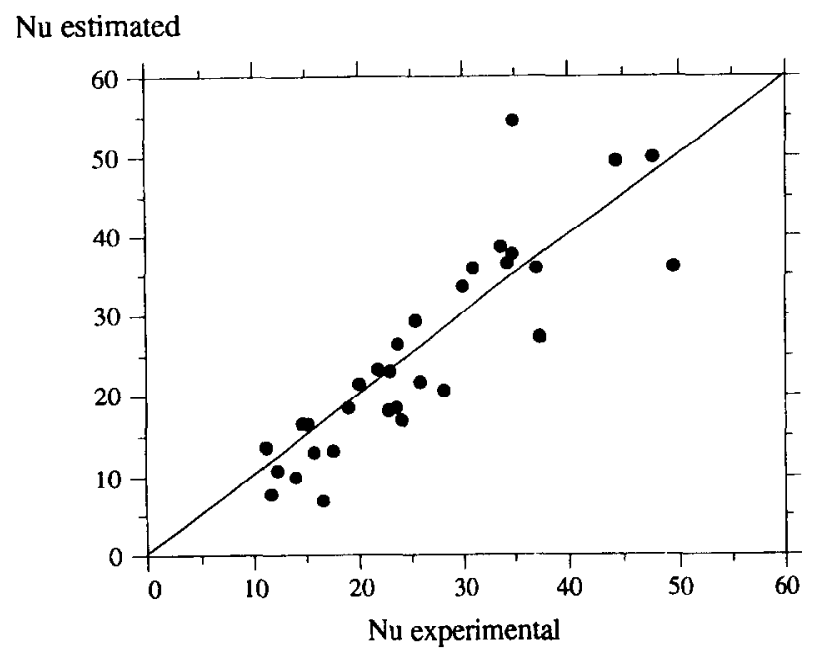

Fig. 2. Prediction of experimental Nusselt numbers considering additive effects of the particle rotational velocity and of the relative fluid-to-particle velocity $\left(N u=N u_{s}+0.64 * R e_{g}^{0.59}\right.$ * $\left.P r_{g}{ }^{0.28}+0.17 * \operatorname{Re}_{g \omega}{ }^{0.71} * \operatorname{Pr}_{g \omega}{ }^{0.42} *\left(r_{p} / R_{t}\right)^{0.28}\right)$. Each of the 32 experimental points is the average of four replicates. results, shown in Fig. 2, are very satisfactory. The regression coefficient is not very high $(0.813)$, but it should be noted that this is partly due to a substantiated scatter in the experimental data. This scatter may be due to experimental difficulties. A uniform coating of the particles is very difficult to obtain in spherical particles and this results in a large deviation in the temperature determinations and therefore in the $h_{f p}$ values ( 1.8 to $27.3 \%$ ). These results show that both the rotational and the relative fluid-to-particle velocities influence the heat transfer rate and, therefore, both contributions should be taken in consideration when describing heat transfer processes in particulate fluid flow.

\section{CONCLUSIONS}

It was concluded that particle density, besides flow rate and fluid viscosity, significantly affects the heat transfer rates for single particles in continuous tube flow. This effect is due to the changes promoted by the particle density on its movements. Both the particle rotational and relative fluid-to-particle velocities affect the boundary layer surrounding the particle and therefore the heat transfer process. Furthermore, it was concluded that these effects could be considered additive, using dimensionless correlations developed individually. These results were obtained at low temperatures, up to $37^{\circ} \mathrm{C}$. For real thermal processing conditions, the relevance of different convective currents would need to be assessed. Predictions of the models presented can only be established as broad estimates.

\section{ACKNOWLEDGEMENTS}

The authors P. N. Baptista, F. A. R. Oliveira and J. C. Oliveira are grateful to Junta Nacional de Investigação Científica e Tecnológica and to the CEC (Flair Programme) for financial support. The authors would like to acknowledge B. Heskitt for invaluable technical support.

\section{REFERENCES}

ASM (1979) Metals Handbook, Vol. 2 - Properties and Selection: Nonferrous Alloys and Pure Metals. Pp. 115-116. American Society for Metals, Mctals Park, $\mathrm{OH}$, USA.

Åström, A. and Bark, G. (1994) Heat transfer between fluid and particles in aseptic processing. Journal of Food Engineering 21, 97-125.

Awuah, G. B., Ramaswamy, H. S. and Simpson, B. K. (1993) Surface heat transfer coefficients associated with heating of food particles in CMC solutions. Journal of Food Process Engineering 16, 39-57.

Balasubramaniam, V. M. (1993) Liquid-to-particle convective heat transfer in aseptic processing systems. Ph.D. thesis, Ohio State University, Columbus, $\mathrm{OH}$, USA. 
Baptista, P. N., Oliveira, F. A. R., Oliveira, J. C. and Sastry, S. K. (1997) Dimensionless analysis of fluid-to-particle heat transfer coefficients. Journal of Food Engineering 31, 199218.

Dignan, D. M., Berry, M. R., Pflug, I. J. and Gardine, I. D. (1989) Safety considerations in establishing aseptic processes for low-acid foods containing particulates. Food Technology 43, 118-121.

Dutta, B. and Sastry, S. K. (1990a) Velocity distributions of food particles suspensions in holding tube flow: experimental and modelling studies on average particles velocities. Journal of Food Science 55, 1448-1453.

Dutta, B. and Sastry, S. K. (1990b) Velocity distributions of food particles suspensions in holding tube flow: Characteristics and fastest-particle velocities. Journal of Food Science 55, 1703-1710.

Heldman, D. R. and Singh, R. P. (1981) Food Process Engineering. AVI Publication Co., Westport, Conneticut, USA.

Heppell, N. J. (1985) Measurement of the liquid-solid heat transfer coefficient during continuous sterilization of liquids containing solids. Presented at the $4 \mathrm{th}$ International Congress of Engineering and Food, Edmonton, Alberta, Canada, July 7-10, 1985.

Mwangi, J. M., Rizvi, S. S. H. and Datta, A. K. (1993) Heat transfer to particles in shear flow: application in aseptic processing. Journal of Food Engineering 19, 55-74.

Moffat, R. J. (1990) Some experimental methods for heat transfer studies. Experimental Thermal and Fluid Science 3. $14-32$.

Noordsij, P. and Rotte, J. W. (1967) Mass transfer coefficients to a rotating and to a vibrating sphere. Chemical Engineering Science 22, 1475--1481.

Palmieri, L., Cacace, D., Dipollina, G. and Dall'Aglio, G (1992) Residence time distribution of food suspensions containing large particles when flowing in tubular systems. Journal of Food Engineering 17, 225-239.

Rao, M. A., Cooley, H. J., Anantheswaran, R. C. and Ennis, R. W. (1985) Convective heat transfer to canned liquid foods in a Steriretort. Journal of Food Science 50, 150-157.
Sablani, S. S. and Ramaswamy, H. S. (1995) Fluid-to-particle heat transfer coefficients in cans during end-over-end processing. Lebensmittel Wissenschaft und Technologie 28, $56-61$

Sastry, S. K., Lima, M., Brim, J., Brunn, T. and Heskitt, B. F. (1990) Liquid-to-particle heat transfer during continuous tube flow: influence of flow rate and particle-to-tube diameter ratio. Journal of Food Processing and Engineering 13, 239-253.

Stoforos, N. G. and Merson, R. L. (1990) Estimating heat transfer coefficients in liquid/particulate canned foods using only liquid temperature data. Journal of Food Science 55, 478-483.

Stoforos, N. G. and Merson, R. L. (1991) Measurement of heat transfer coefficients in rotating liquid/particulate systems. Biotechnology Progress 7, 267-271.

Stoforos, N. G. and Merson, R. L. (1992) Physical property and rotational speed effects on heat transfer in axially rotating liquid/particulate canned foods. Journal of Food Science 57, 749-754.

Walpole, R. E. and Myers, R. H. (1993) Probability and Statistics for Engineers and Scientists. Pp. 319-322. Macmillan Publishing Company, New York, USA.

Zitoun, K. B. (1993) Convective heat transfer coefficients between fluid and cubic particles in continuous tube flow. M.Sc. thesis, Ohio State University, Columbus, $\mathrm{OH}$, USA.

Zitoun, K. B. and Sastry, S. K. (1994a) Determination of convective heat transfer coefficient between fluid and cubic particles in continuous tube flow using non-invasive experimental techniques. Journal of Food Process Engineering 17, $209-228$

Zitoun, K. B. and Sastry, S. K. (1994b) Convective heat transfer coefficient for cubic particles in continuous tube flow using the moving thermocouple method. Journal of Food Process Engineering 17, 229-241. 